\title{
Protective effects of amifostine, curcumin and caffeic acid phenethyl ester against cisplatin-induced testis tissue damage in rats
}

\author{
TOLGA MERCANTEPE ${ }^{1}$, DENIZ UNAL $^{2}$, LEVENT TÜMKAYA $^{1}$ and ZIHNI ACAR YAZICI ${ }^{3}$ \\ ${ }^{1}$ Department of Histology and Embryology, Faculty of Medicine, Recep Tayyip Erdoğan University, Rize 53010; \\ ${ }^{2}$ Department of Histology and Embryology, Faculty of Medicine, Atatürk University, Erzurum 25000; \\ ${ }^{3}$ Department of Medical Microbiology, Faculty of Medicine, Recep Tayyip Erdoğan University, Rize 53010, Turkey
}

Received September 17, 2017; Accepted January 24, 2018

DOI: 10.3892/etm.2018.5819

\begin{abstract}
Cisplatin is an effective antineoplastic drug that is usually used to treat a number of different types of cancer in the clinic. One of the most notable side effects of cisplatin use is infertility. The present study was designed to determine the non-oxidative testicular effects caused by the use of cisplatin in rats. The rats were randomly allocated to the experimental groups. The untreated rats represented the control group (group I) and the treatment groups were as follows: cisplatin alone (group II), cisplatin+amifostine (group III), cisplatin+curcumin (group IV), and cisplatin+caffeic acid phenethyl ester (CAPE; group V). The present study observed that following cisplatin administration, the expression of nuclear factor- $\kappa \mathrm{B}(\mathrm{NF}-\kappa \beta) / \mathrm{p} 65$, caspase-3 and 8-deoxyguanosine $(8-\mathrm{OHdG})$ increased in germinal epithelium and Leydig cells. However, the expression of these markers decreased in groups III-V, most notably in the group treated with amifostine. cisplatin induced-damage was countered by amifostine and curcumin. The results revealed that the activation of NF- $\kappa \mathrm{B}$, caspase-3 and $8-\mathrm{OHdG}$ had a significant role in cisplatin-induced testicular toxicity. Thus, amifostine, curcumin and, to a lesser extent, CAPE have the potential for use as therapeutic adjuvants in cisplatin-induced testis injury.
\end{abstract}

\section{Introduction}

The treatment process of cancer varies according to the type, and it comprises different steps, including surgery, radiotherapy, and chemotherapy. The agents used in chemotherapy have

Correspondence to: Dr Tolga Mercantepe, Department of Histology and Embryology, Faculty of Medicine, Recep Tayyip Erdoğan University, 74 Iki Numaralı Sehitler Caddesi, Islampaşa Mahallesi, Rize 53010, Turkey

E-mail: tolgamercantepe@yahoo.com

Key words: amifostine, caffeic acid phenethyl ester, cisplatin, curcumin, testis different mechanisms of actions. Nevertheless, the agents with the most efficient selective cytotoxicity features spread rapidly in cells with active cell division and cause a variety of toxicities revealed as neutropenia, anemia, thrombocytopenia, hair follicle cell damage, and apoptosis of hemopoietic stem cells $(1,2)$. Some agents, such as cisplatin, taxon, and vinca alkaloids damage the peripheral nervous system, resulting in sensory-motor neuropathy. Also, cisplatin can damage the testicles and cause infertility $(1,2)$.

Despite the fact that cisplatin is one of the most efficient antineoplastic drugs used in the treatment of many cancer types in clinical oncology, the most important side effect restricting its use is dose-dependent toxicity. Infertility is proportional to testicular damage resulting from cisplatin (1-4). In general, infertility problems occur after chemotherapy and radiotherapy. Thus, the protection of reproductive health is an important issue that needs to be resolved in cancer patients with reproduction concerns. In this context, many researchers have classified the chemotherapeutic agents with wide clinical use as having high, intermediate, and low risk (4-6).

Because amifostine reduced cumulative tissue toxicity generated by cisplatin in patients with advanced stage cancer, except for small cell lung carcinoma, it was approved by the food and drug administration (FDA) in the United States in 1996 (7-10). Amifostine has been shown to be effective in preventing the side effects such as nephrotoxicity, ototoxicity, and neurotoxicity in both preclinical and clinical studies.

Curcumin is a diarylheptanoid and exhibits relatively powerful antioxidant, anti-inflammatory, antiproliferative and anti-tumor effects. The phenolic-OH group of curcumin, as well as its $\beta$ diketone derivatives, react with some reactive oxidative species. Thus, curcumin prevents lipid peroxidation and oxidative DNA damage and reduces the release of arachidonic acid as a result of inhibition of oxidative lipoxygenase and cyclooxygenase enzymes. Also, it inhibits the activation of NF- $\mathrm{KB}$ and induces an anti-inflammatory effect (11-13).

CAPE is an active component of propolis extracts and is known to have antioxidant properties (14-16) CAPE exhibits different properties, such as balancing of intracellular calcium and removal of free radicals $(17,18)$. Moreover, it also exhibits antioxidant properties by enhancing the effects of superoxide 
dismutase, glutathione peroxidase, glutathione reductase, and glucose-6-phosphate dehydrogenase stimulation. Due to the aforementioned biological effects of CAPE, it may demonstrate a protective effect in cancer treatment concerning organ and tissue damage associated with chemotherapy $(19,20)$.

The aim of the present study was to investigate in rats the protective efficacies of the antioxidant substances amifostine, curcumin, and CAPE in cisplatin-induced testicular damage and associated infertility that require sperm cryopreservation prior to therapy.

\section{Materials and methods}

Animal study. Male Sprague Dawley rats, (3-4 months old weighing 200-300 g) were procured from the Ataturk University Animal Care and Research Unit (Erzurum, Turkey). All animals received humane care according to the criteria outlined in the 'Guide for the Care and Use of Laboratory Animals' prepared by the National Academy of Sciences and published by the National Institutes of Health. The study was approved by the Ataturk University Institutional Animal Ethical Committee (Erzurum, Turkey) (2013; 36643897-126).

Animal study. The animals were kept at $21 \pm 3^{\circ} \mathrm{C}$ and exposed to $12 \mathrm{~h}$ light/dark cycles. Pellets containing $21 \%$ crude protein (Purina) and water were provided ad libitum. Rats were allocated to five groups of six, which were untreated (group I control) or treated with cisplatin (group II), cisplatin+amifostine (group III), cisplatin+curcumin (group IV) and cisplatin+CAPE (group V).

Drug preparation and experimental protocols. All interventions to each experimental group, except for the control group, were performed in the facilities of the Experiment Animals Research Unit of the University. Group 1 helped to determine baseline values of histopathological parameters. Previous experimental studies demonstrated that at low doses $(1.1-2,5 \mathrm{mg} / \mathrm{kg})$, cisplatin was selectively toxic for spermatogonia. At higher doses $(10-20 \mathrm{mg} / \mathrm{kg})$, cisplatin had toxic effects on the spermatocytes and spermatids in the adluminal compartment. We used cisplatin at $5 \mathrm{mg} / \mathrm{kg}$ to bypass some of the higher dose side effects (21-23). A single dose of $5 \mathrm{mg} / \mathrm{kg}$ cisplatin was given to the indicated groups by intraperitoneal (IP) injection. $400 \mathrm{mg} / \mathrm{kg} / \mathrm{day}$ of amifostine (in ethanol) was applied IP to group III (10), starting $24 \mathrm{~h}$ prior to the application of cisplatin injection and continued for seven days. $100 \mathrm{mg} / \mathrm{kg} /$ day of curcumin (Sigma, St. Louis, MO, USA) dissolved in dimethyl sulfoxide (DMSO) was given orally to group IV $(24,25)$, starting $24 \mathrm{~h}$ before the application of cisplatin injection and continued for seven days. $10 \mu \mathrm{mol} / \mathrm{kg} /$ day of CAPE (Santa Cruz Biotechnology, Inc., Dallas, TX, USA) dissolved in DMSO was applied IP to group V $(17,18)$, starting $24 \mathrm{~h}$ before the application of cisplatin injection and continued for seven days.

Seven days after the application of cisplatin, the rats were sacrificed by cervical dislocation under general anaesthesia induced by $10 \mathrm{mg} / \mathrm{kg}$ xylazine (Rompun, Bayern, Istanbul, Turkey) and $90 \mathrm{mg} / \mathrm{kg}$ ketamine (Ketalar, Eczacıbaşı Co., Istanbul, Turkey). The testes were removed, histologic sections were taken and processed for light and electron microscopic examinations.
The weights of all rats were recorded on day 1 (baseline), before cisplatin administration, and on day 7, after the completion of the study and before sacrifice.

Histological preparation. Testicular tissue sections were fixed in bouin solution and subsequently embedded in paraffin. 4-5 $\mu \mathrm{m}$ thick sections were prepared for hematoxylin-eosin (H\&E), Periodic Acid Schiff (PAS), and Masson trichrome staining (Applichem GmbH, Darmstadt, Germany). Preparations were analyzed under a light microscope (DM6200; Leica Microsystems GmbH, Wetzlar, Germany). Photos were taken using the Olympus DP20 camera (Olympus Corporation, Tokyo, Japan).

Immunohistochemistrigical preparation. Testicular tissue blocks were fixed in $2.5 \%$ formaldehyde and were subsequently embedded in paraffin. 1-3 $\mu \mathrm{m}$ sections were prepared and immunologically stained for NF- $\kappa \mathrm{B} / \mathrm{p} 65$ (1:100, Anti-NF- $\kappa \mathrm{B} / \mathrm{p} 65$ antibody, ab16502; Abcam, Cambridge, UK), caspase-3 (1:100, rabbit anti-caspase 3 polyclonal antibody, ab4051; Abcam) and 8-OHdG (1:50, KOG-HS10E, Dako Envision kit; Japan Institute for the Control of Aging (JaICA), Nikken SEIL Co., Ltd., Shizuoka, Japan), using the Ventana Benchmark GX (USA) device. Then the secondary antibody was applied (UltraView Universal DAB Detection kit, 760-500; Ventana Medical Systems, Inc., Tucson, AZ, USA). Sections were examined under a light microscope and photos were taken as described above.

Stereological analysis. For stereological examination, software (Stereoinvestigator 8; MBF Bioscience, Williston, VT, USA) and camera attachment were used. Counting grid size and frame size were run biased estimated.The measurement area was sampled systematically and randomly over the fractionator probe. $\mathrm{NF}-\kappa \mathrm{B} / \mathrm{p} 65$, caspase -3 , and $8-\mathrm{OHdG}$ positive cells were counted at $\mathrm{x} 40$ magnification. Slides were examined without any randomising in their orientation. Positive cells were determined as described previously (26-28). Eventually, the mean numerical density of $\mathrm{NF}-\kappa \mathrm{B} / \mathrm{p} 65$, caspase-3, and $8-\mathrm{OHdG}$ positive cell were estimated by the following formula:

$$
\mathrm{Nv}=\frac{Q}{S x A}
$$

Nv: numerical density, Q: total markers counted, S: no. of sampling sides, A: counting frame area.

Transmission electron microscopy. The tissues were fixed in $100 \mathrm{mM}$ phosphate buffer containing $2.5 \%$ glutaraldehyde for $1.5 \mathrm{~h}$ at $4^{\circ} \mathrm{C}$. The samples were rinsed in phosphate buffer and stored at $4^{\circ} \mathrm{C}$ for later processing. These were post-fixed in $1 \%$ osmium tetroxide, dehydrated in ethanol series and then embedded in Epoxy resin (Araldite CY212) kit (Agar Scientific, Ltd., Stansted, UK). 750 nano meter thick sagittal sections were cut and stained with toluidine blue for light microscopic analysis. Stained sections were visualized and imaged using a Leica DM 6400 (Leica Microsystems $\mathrm{GmbH}$ ). For electron microscopic analysis, 40-70 nm thick sections were cut using ultramicrotome (LKB Nova, Sweden) set on 200-mesh copper or nickel grids. The sections were stained with uranyl acetate and Reynold's lead citrate for 
transmission electron microscopy. Imaging was achieved with the JEOL 100SX transmission electron microscope, (JEOL, Ltd., Tokyo, Japan) and photographed (Kodak 4489; Kodak, Rochester, NY, USA).

Statistical analysis. The numerical density of NF- $\mathrm{kB} / \mathrm{p} 65$, 8-OHdG, and caspase-3 positive cells was calculated. Data were expressed as mean \pm SEM (standard error of the mean). Statistical analysis was performed using one-way analysis of variance followed by Duncan's test for each paired experiment value of $\mathrm{P}<0.05$, which is considered to be significant. Body weights were expressed as mean \pm SEM. Statistical analysis was performed using paired samples $t$ test for each paired experiment value of $\mathrm{P}<0.05$, which was considered to indicate a statistically significant difference. The package used for statistical analyses was the IBM SPSS Statistics v20 (IBM Corp., Armonk, NY, USA).

\section{Results}

Light microscopy results. The testicular structure of the control group was normal (Figs. 1 and 2). The connective tissue, vascular structures, and Leydig cells formed a typical structure. The basal lamina of the testicular seminiferous tubules was of usual regularity (Figs. 1A and B, 2A).

The testicular tissue of the cisplatin group was extensive oedematous as a result of the loss of the germinal epithelial cells of the seminiferous tubules. In the remaining germinative epithelium, the connection between spermatocytes and spermatogonia with dense chromatin containing atypical nuclei was lost. Also, the numbers of spermatozoa and spermatids were lower than those of the control group. The basal lamina of the seminiferous tubules was degenerate (Fig. 2B). There was intense hyalinization of the interstitial spaces. In addition, there was vascular congestion in the interstitial spaces and tunica albuginea. The Leydig cells had fragmented nuclei, and their number was low in the interstitial spaces. (Figs. 1C, 2B).

The testicular tissue structures of the amifostine group (group III) had normal germinal epithelial cells and Leydig cells. The basal lamina of the testicular seminiferous tubules was regular (Figs. 1C, 2C).

In the curcumin-treated group, there was little inter-epithelial cell vacuolization of the seminiferous tubules. The spermatogonia and spermatids were normal. Spermatozoa in the seminiferous tubules were far more numerous than the cisplatin group. Hyalinization of the interstitial space was less intense than that of the cisplatin group. (Figs. 1E, 2D). Similarly, the regularity of the basal layer of the seminiferous tubules was less than the corresponding cisplatin group (Fig. 2D).

Microscopically, in the testicular tissue sections obtained from group $\mathrm{V}$, the seminiferous tubules showed irregularity. Hyalinization of the connective tissue decreased, which was similar to the cisplatin treatment group (group IV) (Figs. 1E, 2E). The germinal epithelium had a thickness close to those of the control group, and the edema was reduced between the serial cells. However, the spermatids were located in both the adluminal and luminal compartments. They were similar to the control and amifostine groups. The basal lamina of the seminiferous tubules was regular.
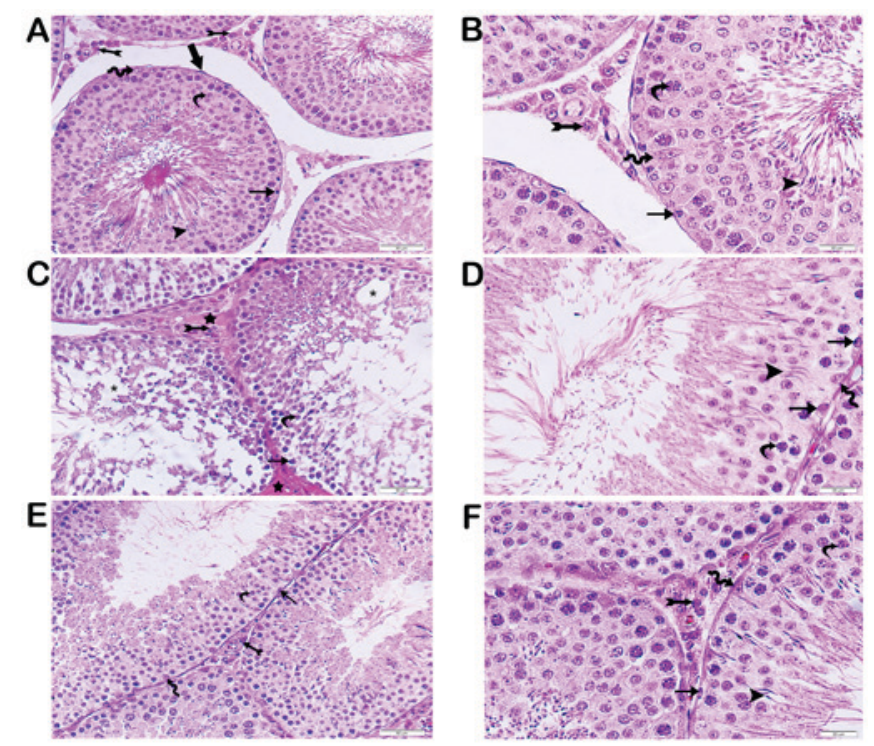

Figure 1. Light microscope images of testicular tissue by hematoxylin and eosin staining. (A) Control group (magnification, x20). (B) Control group (magnification, $\mathrm{x} 40$ ). (C) Cis applied group: Atrophic seminiferous tubules (magnification, $\mathrm{x} 40$ ). (D) Cis+amifostine applied group (magnification, $\mathrm{x} 40$ ). (E) Cis+curcumin applied group (magnification, x20). (F) Cis+CAPE applied group (magnification, $\mathrm{x} 40$ ). Sertoli cells are indicated by spirally arrows; basal lamina of the seminiferous tubule with the myoepithelial cell are indicated by an arrow; spermatogonia are indicated by a thin arrow; spermatids are indicated by an arrowhead; Leydig cells are indicated by a tailed arrow; primary spermatocytes are indicated by curved arrows; Hyalinized interstitial areas are indicated by a star; Oedematous fields are indicated by an asterisk; Cis, cisplatin; CAPE, caffeic acid phenethyl ester.

Immunohistochemical (IHC) results. IHC was performed to determine the expression of various proteins (Figs. 3, 4 and 5). There was intense cytoplasmic staining for NF- $\mathrm{BB} / \mathrm{p} 65$, caspase-3 and 8-OHdG in the germinal epithelium of the seminiferous tubules, particularly in type A and type B spermatogonia, primary spermatocytes and spermatids in the cisplatin group (Figs. 3B, 4B and 5B) (Table I). On the other hand, sections from group III were negative for these markers (Figs. 3C, 4C and 5C) (Table I), as were those of group IV (Figs. 3D, 4D, and 5D) (Table I), except for the weak cytoplasmic staining in Sertoli cells and spermatids in the latter group. Partial cytoplasmic staining was observed in the germinal and Sertoli cells in group V (Figs. 3E, 4E, and 5E) (Table I).

Electron microscopy results. The basal lamina of the seminiferous tubules of the sections had a regular fine structure under transmission electron microscopy (Fig. 6A) in the control group. On the other hand, the corresponding structures in the cisplatin group showed degeneration. Also, apoptotic spermatogonia and spermatocytes were present. Fragmented spermatogonia and spermatid nuclei were also observed (Figs. 6B-D). The nucleolus of the spermatogonia was condensed and lost its stellar appearance (Fig. 6B-D). Vacuoles occurred as a result of cytoplasmic loss were seen in spermatocytes and spermatogonia (Fig. 6B-D). Apoptotic spermatids were also noted. Mitochondrial vacuolizations were also detected in spermatogonia and spermatocytes (Fig. 6B-D).

Electron microscopic examination of testicular sections of group III revealed normal basal lamina (Fig. 6E). Spermatogonium and spermatocytes with typical fine 
Table I. Immunohistochemistry positivity numerical density.

\begin{tabular}{lcrr}
\hline Group & $\begin{array}{c}\text { NF- } \kappa \mathrm{B} \\
\text { numerical density }\left(\mathrm{mm}^{2}\right)\end{array}$ & $\begin{array}{c}\text { Caspase-3 } \\
\text { numerical density }\left(\mathrm{mm}^{2}\right)\end{array}$ & $\begin{array}{c}8-\mathrm{OHdG} \\
\text { numerical density }\left(\mathrm{mm}^{2}\right)\end{array}$ \\
\hline Control & $5 \pm 1.15$ & $5.5 \pm 1.8$ & $7.16 \pm 2.35$ \\
cisplatin & $142.33 \pm 14.01^{\mathrm{a}}$ & $77.33 \pm 8.14^{\mathrm{a}}$ & $79 \pm 5.63^{\mathrm{a}}$ \\
cisplatin+amifostine & $7.5 \pm 1.33^{\mathrm{b}}$ & $17.5 \pm 2.83^{\mathrm{b}}$ & $10.5 \pm 1.78^{\mathrm{b}}$ \\
cisplatin+curcumin & $15.17 \pm 2.19^{\mathrm{b}}$ & $23.5 \pm 3.89^{\mathrm{b}}$ & $23.83 \pm 4.57^{\mathrm{b}}$ \\
cisplatin+CAPE & $23.33 \pm 4.93^{\mathrm{b}}$ & $29.5 \pm 3.93^{\mathrm{b}}$ & $26.33 \pm 5.05^{\mathrm{b}}$ \\
\hline
\end{tabular}

${ }^{\mathrm{a}} \mathrm{P}<0.05$ vs. control group; ${ }^{\mathrm{P}}<0.05$ vs. cisplatin group; Duncan test $(\alpha=0.05)$. Mean \pm standard error. NF- $x \beta$, nuclear factor- $\varkappa \mathrm{B} ; 8-\mathrm{OHdG}$, 8-deoxyguanosine; CAPE, caffeic acid phenethyl ester.

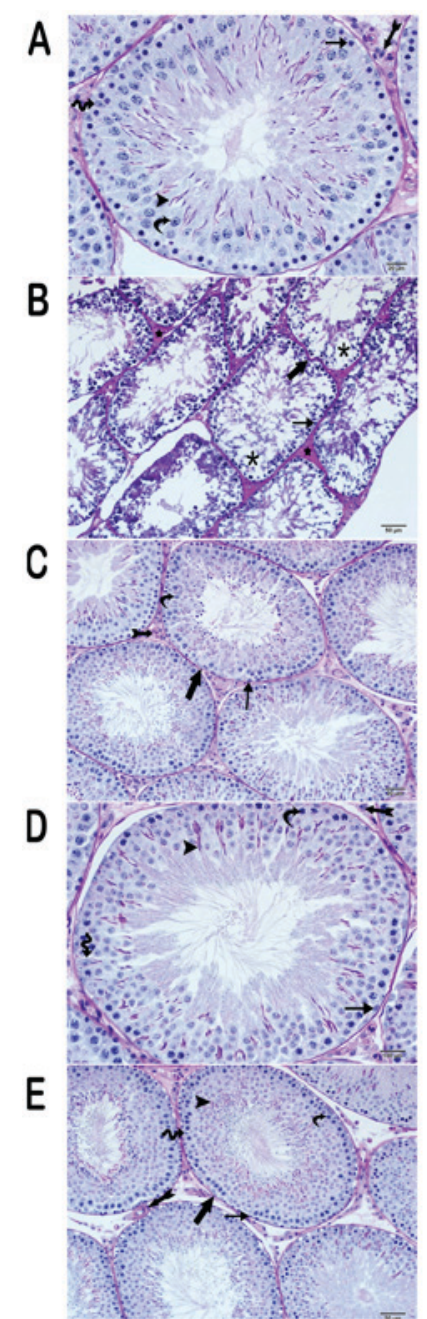

Figure 2. Light microscope images of testicular tissue with Periodic Acid Schiff staining. (A) Control group (magnification, 40x). (B) Cis applied group: Atrophic seminiferous tubules. Irregular basal lamina of the seminiferous tubules (indicated by an arrow). Spermatogonia with condensed chromatin (indicated by a thin arrow; magnification, 20x). (C) Cis+amifostine applied group: Regular basal lamina of the seminiferous tubule (indicated by an arrow; magnification, 20x). (D) Cis+curcumin applied group (magnification, $\mathrm{x} 40$ ). (E) Cis+CAPE applied group (magnification, 20x). Sertoli cells are indicated by spirally arrows; basal lamina of the seminiferous tubule with the myoepithelial cell are indicated by an arrow; spermatogonia are indicated by a thin arrow; spermatids are indicated by an arrowhead; Leydig cells are indicated by a tailed arrow; primary spermatocytes are indicated by curved arrows; Hyalinized interstitial areas are indicated by a star; Oedematous fields are indicated by an asterisk; Cis, cisplatin; CAPE, caffeic acid phenethyl ester.

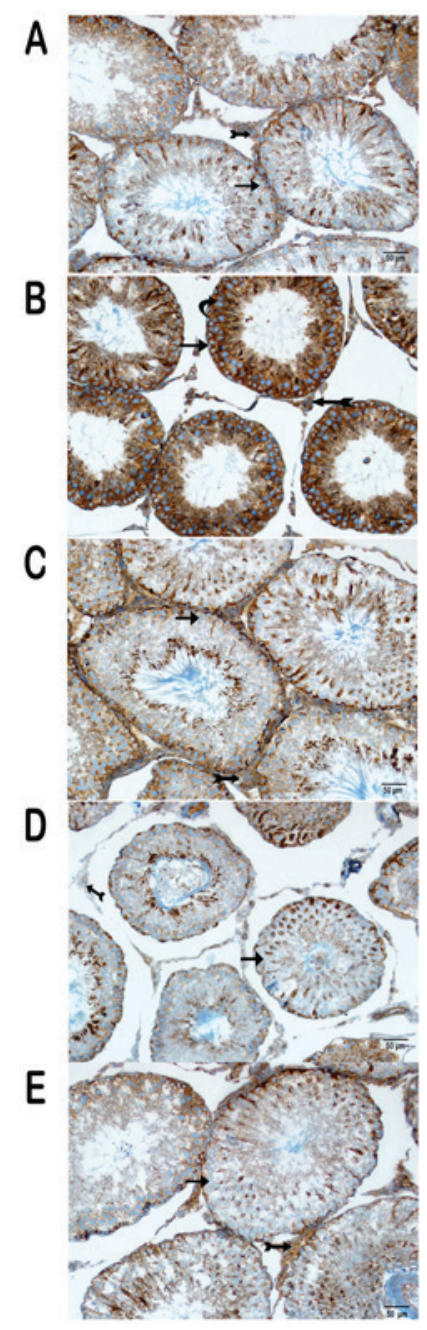

Figure 3. Light microscope images of testicular tissue with nuclear factor- $\kappa \mathrm{B} / \mathrm{p} 65$ staining. (A) Control group (magnification, 20x). (B) Cis applied group (magnification, 20x). (C) Cistamifostine applied group (magnification, 20x). (D) Cis+curcumin applied group (magnification, 20x) (E) Cis+CAPE applied group (magnification, 20x). Spermatids are indicated by an arrowhead; Leydig cells are indicated by a tailed arrow; primary spermatocytes are indicated by curved arrows; (arrowhead); Germinal epithelium cells are indicated by thin arrows; Cis, cisplatin; CAPE, caffeic acid phenethyl ester.

structure were observed. Mitochondria with an intense matrix and typical fine structure were seen in spermatogonia and 


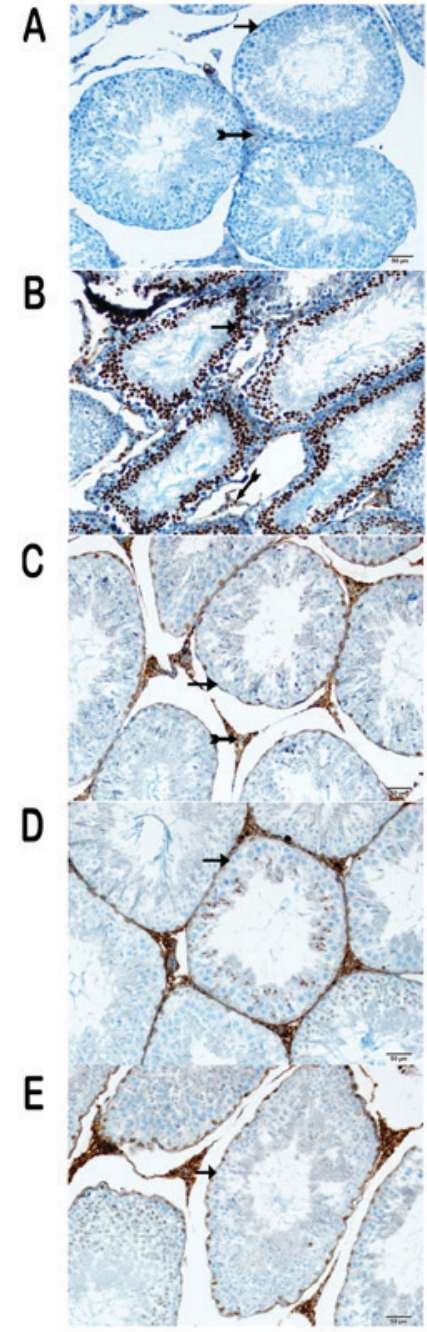

Figure 4. Light microscope images of testicular tissue with caspase-3 staining. (A) Control group (magnification, 20x). (B) Cis applied group (magnification, 20x). (C) Cis+amifostine applied group (magnification, 20x). (D) Cis+curcumin applied group (magnification, 20x). (E) Cis+CAPE applied group (magnification, 20x). Spermatids are indicated by an arrowhead; Leydig cells are indicated by a tailed arrow; primary spermatocytes are indicated by curved arrows; (arrowhead); Germinal epithelium cells are indicated by thin arrows; Cis, cisplatin; CAPE, caffeic acid phenethyl ester.

spermatocytes (Fig. 6F). The Leydig cells had normal fine structure and mitochondria with typical crystals and intense matrix content.

Group IV sections displayed normal myoepithelial cells with a normal fine structure of the basal lamina. Spermatogonia and spermatocytes with a typical fine structure were also observed. The mitochondria had an intense matrix with typical fine structure. The mitochondria of the Leydig cells had a normal fine structure (Fig. 6E).

Sections of group V revealed typical myoepithelial cells with a fine structure of the basal lamina. Although the appearance of the spermatogonia and spermatocytes on the basal lamina were regular, vacuoles were present in spermatogonia and spermatocytes in small numbers (Fig. 6F).

Statistical analysis. With the exception of the controls, there was a statistically significant decrease in the body weights of the animals after the treatment $(\mathrm{P}<0.05)$ (Table II).

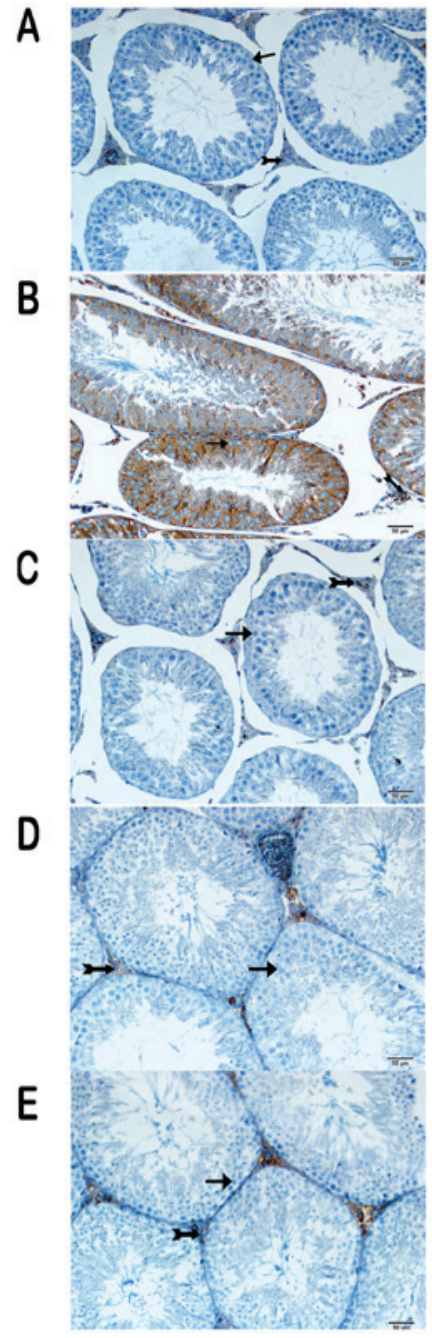

Figure 5. Light microscope images of testicular tissue with 8-OHdG staining. (A) Control group (magnification, 20x). (B) Cis applied group (magnification, 20x). (C) Cis+amifostine applied group (magnification, 20x). (D) Cis+curcumin applied group (magnification, 20x). (E) Cis+CAPE applied group (magnification, 20x). Spermatids are indicated by an arrowhead; Leydig cells are indicated by a tailed arrow; primary spermatocytes are indicated by curved arrows; (arrowhead); Germinal epithelium cells are indicated by thin arrows; Cis, cisplatin; CAPE, caffeic acid phenethyl ester.

The results also revealed larger NF- $\kappa \mathrm{B} / \mathrm{p} 65$, caspase-3 and 8-OHdG staining of the germinal epithelium of the cisplatin group compared to the control group $(\mathrm{P}<0.05)$. The cisplatin+amifostine group showed less staining for $\mathrm{NF}-\mathrm{\kappa B} / \mathrm{p} 65(\mathrm{P}<0.05)$, caspase-3 and 8-OHdG expression than the cisplatin group $(\mathrm{P}<0.05)$. The cisplatin+curcumin and cisplatin+CAPE groups displayed less NF- $\kappa \mathrm{B} / \mathrm{p} 65(\mathrm{P}<0.05)$, caspase- 3 and $8-\mathrm{OHdG}$ expression than the cisplatin group $(\mathrm{P}<0.05)$. Intensity and distribution of staining for the same markers in cisplatin+amifostine sections were similar to those of the cisplatin+curcumin and CAPE group $(\mathrm{P}>0.05)$ (Table I).

\section{Discussion}

Survival of young male cancer patients has increased by $75 \%$ over the last 20 years as a result of early diagnosis and intervention $(6,29,30)$. Typically, infertility occurs after chemotherapy and radiotherapy. Currently, semen 
Table II. Body weights of rats before and after treatment.

Pre-treatment body weights (gram)

(mean \pm standard deviation)

\begin{tabular}{lll}
\hline Control & $250.00 \pm 16.58$ & $262.67 \pm 13.53$ \\
cisplatin & $259.33 \pm 33.33$ & $219.67 \pm 32.49^{\mathrm{a}}$ \\
cisplatin+amifostin & $260.33 \pm 29.38$ & $216.00 \pm 27.33$ \\
cisplatin+curcumin & $238.67 \pm 17,77$ & $206.83 \pm 22.27$ \\
cisplatin+CAPE & $260.50 \pm 21.77$ & $218.67 \pm 22.37^{\mathrm{a}}$
\end{tabular}

Post-treatment body weights (gram) (mean \pm standard deviation)

${ }^{a} \mathrm{P}<0.05$ for Pre-treatment group vs. post-treatment group, paired samples t-test. CAPE, caffeic acid phenethyl ester.

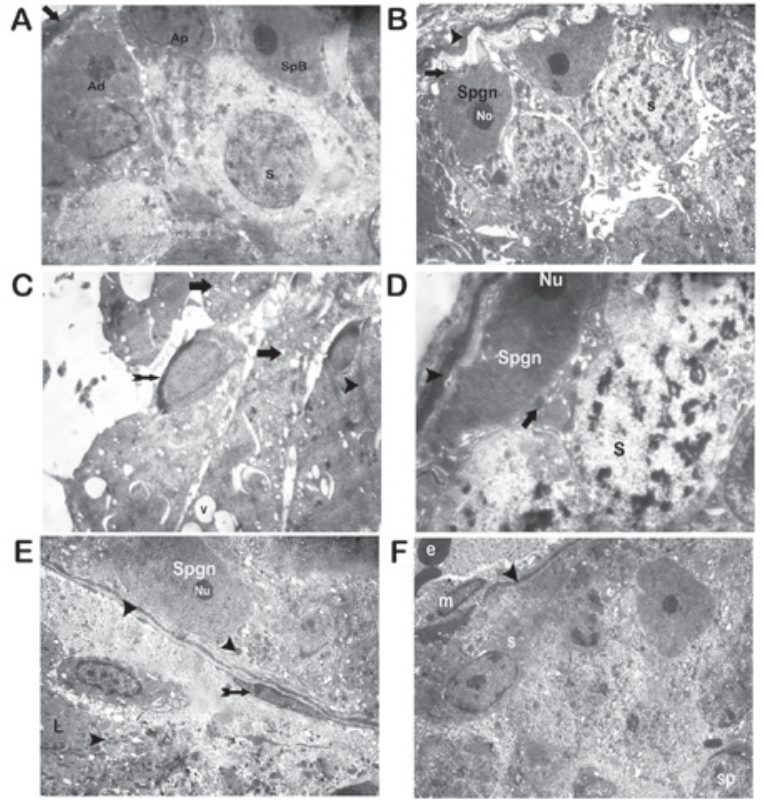

Figure 6. Transmission electron microscope micrographs of testicular tissue with Uranyl acetate and Reynold's lead citrate staining. (A) Control group A normal basal lamina of the seminiferous tubule with the myoepithelial cell (indicated by an arrow), containing dark type A spermatogonia (indicated by Ad); and Pale type A spermatogonia (indicated by Ap) and type B spermatogonia (indicated by $\mathrm{SpB}$ ). Spermatocytes are indicated by s (magnification, 3,000x). (B) Cis applied group: Deterioration of integrity between spermatogonia and degenerative basal lamina were monitored (indicated by arrowheads); Fragmented nucleus (indicated by arrows) and Nucleolus (indicated by No; magnification, 3,000x). (C) C is applied group: Degenerated mitochondria (indicated by arrows); spermatid nuclear caps (indicated by tailed arrow); ring formation (indicated by arrowhead); vacuoles (indicated by v; magnification, 3,000x). (D) Cis+amifostine applied group: Spermatocytes (indicated by s); typical basal lamina was observed (indicated by arrowheads); spermatogonia (indicated by Spgn); typical mitochondria with mitochondrial membranes were monitored (indicated by arrows); Nucleolus (indicated by $\mathrm{Nu}$; magnification, 3,000x). (E) Cis+curcumin applied group: Typical mitochondria with dense mitochondrial were observed (indicated by arrowheads); nucleus (indicated by $\mathrm{Nu}$ ); myoepithelial cell (indicated by tailed arrow); the regular Leydig cell was seen (indicated by L; magnification, 3,000x). (F) Cis+CAPE applied group; Mitochondria (indicated by $\mathrm{m}$ ); basal lamina (indicated by arrowheads); spermatocytes (indicated by s); spermatids (indicated by sp); erythrocyte (indicated by e; magnification, 2,500x). Cis, cisplatin; CAPE, caffeic acid phenethyl ester.

cryopreservation has accompanied the treatment of cancer patients to partially compensate infertility. However, sperm cryopreservation has shortages including low fertilization, genetic anomalies due to DNA breakages, ethical issues, and high cost. Therefore, more efficient alternative approaches are needed $(6,29,30)$.

Cisplatin is an essential antineoplastic agent that is widely used in the treatment of solid tumors. cisplatin interferes with DNA base pair cross-linking, resulting in cytotoxicity of proliferating cells $(5,12,31-33)$.

Agents causing DNA damage show more cytotoxic effects on proliferating cells (29,34-37). Spermatogenesis is a natural process, which is characterized by cell division in the testis. Recent studies have reported that the toxic effect of cisplatin on the testis results in a variety of anomalies, such as atrophic seminiferous tubules, germinal epithelium damage due to apoptosis and necrosis, loss of connections between the spermatogonium and basal lamina, inflammation and damage in the peritubular area $(31,32,38-46)$. Our histopathological findings appear to support the cytotoxic effects of cisplatin except for peritubular inflammation. However, we determined that cisplatin causes the cytoplasmic expression of the transcription factors NF- $\kappa \mathrm{B} / \mathrm{p} 65$ and $8-\mathrm{OHdG}$ in spermatogenic cells and Sertoli cells in the germinal epithelium of the seminiferous tubules, and an increase in nuclear caspase-3 expression in other spermatogonial cells. On the contrary, the expression of $\mathrm{NF}-\kappa \beta$, caspase -3 , and $8-\mathrm{OHdG}$ decreased in all cisplatin groups treated with amifostine. In the cisplatin group alone, we observed degenerated basal lamina, apoptotic spermatogonia, spermatocytes, fragmented spermatogonia, and spermatid nuclei under electron microscopy. The spermatocytes were swollen and lost their stellar appearance, demonstrating a condensed nucleolus, cytoplasm and perinuclear area.

In the literature, cisplatin-induced cellular and tissue damage have been attributed to its oxidative stress. However, no other mechanisms of action have been investigated by histopathological studies $(33,41,43,47,48)$.

In an vitro study by Yang et al, cisplatin induced apoptosis in concentrations of 10-50 $\mu \mathrm{M}$ in tubular cells (45). Apoptosis is reported to be induced via the MAPK signaling pathways. The MAPK signaling pathway regulates proliferation, differentiation, and survival of cells. The MAPK signaling pathway incorporates serine/threonine kinases of parallel cascades. These parallel cascades are activated by different extracellular physical and chemical stresses. There are three main parallel MAPK signaling cascades: the ERK pathway, protein kinase (JNK GENE/FATH) pathway (which is activated by p38) and 
Jun N-terminal Kinase/stress pathway. The ERK pathway is typically activated by extracellular growth factors and is associated with cell viability and cell death. P38 and JNK GENE/FATH paths are activated by oxidation, UV irradiation, hyperosmolality and inflammatory cytokines that are associated with cell death. cisplatin induces its toxicity in vitro and in vivo by activating these three MAPK signaling pathways. The ERK and P38 signaling pathways activate the production of TNF- $\alpha$. ERK controls cell apoptosis and activates caspase-3 (38,43-47).

Several studies have reported that cisplatin activates caspase-3 via the ERK pathway. The caspase cascade plays a key role in inducing apoptosis. In particular, activation of caspase- 3 is an irreversible step that induces apoptosis. For this reason, studies have used caspase-3 expression to evaluate apoptotic cells $(3,5,31-33,36,38,41-45,48,49)$. In our study, we confirmed that the number of caspase- 3 positive cells in the cisplatin group significantly increased compared to cells in the control group (Table I, $\mathrm{P}<0,05$ ). There was no significant difference between group III and the control group (Table I, P>0.05). There was also no significant difference between group III (Table I, P $>0.05$ ) and both groups IV and V (Table I, P>0.05).

The Ras oncogenic protein plays a key role in the ERK signaling pathway. Mutations of its gene in cancers induce distortion of GTP. Thus, although an impact on the ERK pathway was expected from an efficient chemotherapeutic agent such as cisplatin, prevention of the distortion of GTP development depends on the Ras gene mutation in healthy cells in the testicular tissue with active cell division such as spermatogenesis, which is essential for fertility. Amifostine, curcumin, and CAPE have previously been reported to significantly decrease caspase-3/caspase- 8 activity (50-57). In the present study, we observed that amifostine and curcumin prevented caspase- 3 activation and protected both testicular tissue and spermatogenesis and that CAPE provided partial protection.

CAPE has been reported to reduce apoptosis $(14,17,20,47)$. Conversely, Severi-Aguiar et al (58) noticed that $10 \mathrm{mg}$ of propolis/kg/day induced $\mathrm{Cx} 43$ upregulation and caused morphological damage to germ cells, Sertoli cells, and Leydig cells. They observed that apoptotic cells were present in the germinal epithelium of the testes in a dose-dependent manner in their studies. In our study, as in other studies, we found that apoptosis was reduced by cisplatin significantly despite the presence of low level of caspase-3 positivity.

The toxicity induced by cisplatin on the testis via the JNK/SAPK pathways has not yet been investigated thus far. cisplatin triggers p38 activation via free oxygen radicals (hydroxyl radicals). It was reported in the literature that $\mathrm{p} 38$ activation causes oxidative stress, which results in damage to the epithelial cells of the seminiferous tubules by the formation of free oxygen radicals.

Cisplatin also induces the formation of reactive oxygen species (ROS) in mitochondria, by activating NADPH oxidase and the xanthine oxidase. ROS-induced nuclear and mitochondrial DNA damage could be detected by 8 -OHdG. Therefore, 8 -OHdG was used to detect damage caused by cellular oxidative stress. It has been established that ROS induced damage is counteracted by antioxidants, such as CAPE, vitamin C and vitamin E $(19,33,38,41,59)$. Bhimani et al reported that CAPE decreased the tumor promoter-mediated oxidative processes which decreased 8-OHdG (60). Some studies demonstrated that curcumin treatment significantly decreased 8-OHdG (61). There are no studies addressing the effects of amifostine on 8-OHDG. However, previous studies have reported that amifostine acts as a potent free radical scavenger giving free radicals hydrogen ions $(9,10,55,62)$. In our study, the number of 8 -OHdG positive cells in the cisplatin group was significantly higher than those in the control group (Table I, $\mathrm{P}<0.05$ ). There was no significant difference between group $\mathrm{V}$ and control group (Table I, $\mathrm{P}>0.05$ ), nor was there a significant difference between groups III and IV (Table I, P>0.05) and V (Table I, $\mathrm{P}>0.05$ ). In accordance with the previous reports, we observed that the antioxidants CAPE, amifostine, and curcumin protect cells from ROS.

Free radicals generated by the MAPK pathways activate the transcription factor, $\mathrm{NF}-\mathrm{\kappa B} / \mathrm{p} 65$, resulting in apoptosis. In this study, consistent with other studies, the number of $\mathrm{NF}-\kappa \mathrm{B} / \mathrm{p} 65$-positive cells in the cisplatin group was significantly higher than the control group (Table II, $\mathrm{P}<0.05$ ). There are no studies investigating the effects of amifostine, curcumin, and CAPE on NF-KB induced by cisplatin toxicity. However, Schwertheim et al (63) reported curcumin downregulation of NF- $\kappa B$ activity. In our findings, there was no significant difference between group $\mathrm{V}$ and the control group (Table I, P>0.05), nor was there a significant difference between groups III and IV (Table I, P>0.05) and V (Table I, P>0.05). Recent studies revealed that NF- $\mathrm{\kappa B} / \mathrm{p} 65$ could play a regulatory role in the cases of oxidative stress. In addition to cellular damage of the seminiferous tubules caused by cisplatin, we also observed thickening of the basal lamina and distortion of its integrity.

In conclusion, we showed different mechanisms of damage in the testis at play resulting from cisplatin, and their reversal by the antioxidants amifostine, curcumin and, to a lesser extent, CAPE. Further studies are needed to determine if amifostine and cisplatin have an antagonistic effect on cancerous cells.

\section{References}

1. Sabanegh ES Jr and Ragheb AM: Male fertility after cancer. Urology 73: 225-231, 2009.

2. Schrier RW, Wang W, Poole B and Mitra A: Acute renal failure: Definitions, diagnosis, pathogenesis and therapy. J Clin Invest 114: 5-14, 2004.

3. Amin A and Hamza AA: Effects of roselle and ginger on cisplatin-induced reproductive toxicity in rats. Asian J Androl 8: 607-612, 2006

4. Colpi GM, Contalbi GF, Nerva F, Sagone P and Piediferro G: Testicular function following chemo-radiotherapy. Eur J Obstet Gynecol Reprod Biol 113 (Suppl 1): S2-S6, 2004.

5. Cherry SM, Hunt PA and Hassold TJ: cisplatin disrupts mammalian spermatogenesis, but does not affect recombination or chromosome segregation. Mutat Res 564: 115-128, 2004.

6. Dohle GR: Male infertility in cancer patients: Review of the literature. Int J Urol 17: 327-331, 2010.

7. Agarwal A and Prabakaran SA: Mechanism, measurement and prevention of oxidative stress in male reproductive physiology 43: 963-974, 2005.

8. Tokatli F, Uzal C, Doganay L, Kocak Z, Kaya M, Ture M, Kurum T, Alkaya F, Karadag H and Kutlu K: The potential cardioprotective effects of amifostine in irradiated rats. Int J Radiat Oncol Biol Phys 58: 1228-1234, 2004.

9. Uzal C, Durmus-Altun G, Caloglu M, Ergülen A, Altaner S and Yigitbasi NO: The protective effect of amifostine on radiation-induced acute pulmonary toxicity: Detection by 99mTc-DTPA transalveolar clearances. Int J Radiat Oncol Biol Phys 60: 564-569, 2004 
10. Wasserman TH and Brizel DM: The role of amifostine as a radioprotector. Oncology (Williston Park) 15: 1349-1354, 2001

11. Choudhary D, Chandra D and Kale RK: Modulation of radioresponse of glyoxalase system by curcumin. J Ethnopharmacol 64: 1-7, 1999.

12. Devasena T, Rajasekaran KN and Menon VP: Bis-1,7-(2-hydroxy phenyl)-hepta-1,6-diene-3,5-dione (a curcumin analog) ameliorates $\mathrm{DMH}$-induced hepatic oxidative stress during colon carcinogenesis. Pharmacol Res 46: 39-45, 2002.

13. Pan MH, Huang TM and Lin JK: Biotransformation of curcumin through reduction and glucuronidation in mice. Drug Metab Dispos 27: 486-494, 1999.

14. Uz E, Söğüt S, Sahin S, Var A, Ozyurt H, Güleç M and Akyol O The protective role of caffeic acid phenethyl ester (CAPE) on testicular tissue after testicular torsion and detorsion. World J Urol 20 : 264-270, 2002.

15. Grunberger D, Banerjee R, Eisinger K, Oltz EM, Efros L, Caldwell M, Estevez V and Nakanishi K: Preferential cytotoxicity on tumor cells by caffeic acid phenethyl ester isolated from propolis. Experientia 44: 230-232, 1988

16. Akyol S, Akbas A, Butun I, Toktas M, Ozyurt H, Sahin S and Akyol O: Caffeic acid phenethyl ester as a remedial agent for reproductive functions and oxidative stress-based pathologies of gonads. J Intercult Ethnopharmacol 4: 187-191, 2015.

17. Dilber Y, Inan S, Ercan GA and Sencan A: The role of CAPE in $\mathrm{PI} 3 \mathrm{~K} / \mathrm{AKT} / \mathrm{mTOR}$ activation and oxidative stress on testis torsion. Acta Histochem 118: 31-37, 2016.

18. Ogeturk M,Kus I, Colakoglu N,Zararsiz I, Ilhan N and Sarsilmaz M: Caffeic acid phenethyl ester protects kidneys against carbon tetrachloride toxicity in rats. J Ethnopharmacol 97: 273-280, 2005.

19. Kus I, Colakoglu N, Pekmez H, Seckin D, Ogeturk M and Sarsilmaz M: Protective effects of caffeic acid phenethyl ester (CAPE) on carbon tetrachloride-induced hepatotoxicity in rats. Acta Histochem 106: 289-297, 2004.

20. Tolba MF, Omar HA, Azab SS, Khalifa AE, Abdel-Naim AB and Abdel-Rahman SZ: Caffeic acid phenethyl ester: A review of its antioxidant activity, protective effects against ischemia-reperfusion injury and drug adverse reactions. Crit Rev Food Sci Nutr 56 2183-2190, 2016

21. Ciftci O, Beytur A, Cakir O, Gurbuz N and Vardi N: Comparison of reproductive toxicity caused by cisplatin and novel platinum-N-heterocyclic carbene complex in male rats. Basic Clin Pharmacol Toxicol 109: 328-333, 2011.

22. Boekelheide K: Mechanisms of toxic damage to spermatogenesis. J Natl Cancer Inst Monogr: 6-8, 2005

23. Meistrich ML, Finch M, Cunha MF, Hacker U and Au WW: Damaging effects of fourteen chemotherapeutic drugs on mouse testis cells damaging effects of fourteen chemotherapeutic drugs on mouse testis 42: 122-131, 1982

24. Jain KK: The handbook of neuroprotection, 2011

25. Ozgen SÇ, Dökmeci D, Akpolat M, Karadağ CH, Gündüz O, Erbaş H, Benian O, Uzal C and Turan FN: The protective effect of curcumin on ionizing radiation-induced cataractogenesis in rats. Balkan Med J 29: 358-363, 2012.

26. Kalkan Y, Kapakin KA, Kara A, Atabay T, Karadeniz A, Simsek N, Karakus E, Can I, Yildirim S, Ozkanlar S and Sengul E: Protective effect of panax ginseng against serum biochemical changes and apoptosis in kidney of rats treated with gentamicin sulphate. $\mathrm{J} \mathrm{Mol}$ Histol 43: 603-613, 2012

27. Mercantepe T, Unal D, Selli J, Mercantepe F and Unal B: Protective effects of estrogen and bortezomib in kidney tissue of post-menopausal rats: An ultrastructural study. Ren Fail 38: 1129-1135, 2016.

28. Selli J, Unal D, Mercantepe F, Akaras N, Kabayel R, Unal B and Atilay H: Protective effects of beta glucan in brain tissues of post-menopausal rats: A histochemical and ultra-structural study. Gynecol Endocrinol 32: 234-239, 2016

29. Bray F, Richiardi L, Ekbom A, Pukkala E, Cuninkova M and Møller H: Trends in testicular cancer incidence and mortality in 22 European countries: Continuing increases in incidence and declines in mortality. Int J Cancer 118: 3099-3111, 2006.

30. International Agency for Research on Cancer: World cancer report 2008, 2008.

31. Duale N, Lindeman B, Komada M, Olsen AK, Andreassen A, Soderlund EJ and Brunborg G: Molecular portrait of cisplatin induced response in human testis cancer cell lines based on gene expression profiles. Mol Cancer 6: 53, 2007.

32. Mohammadnejad D, Abedelahi A, Soleimani-rad J, Mohammadi-roshandeh A, Rashtbar $\mathrm{M}$ and Azami A: Degenerative effect of cisplatin on testicular germinal epithelium. Adv Pharm Bull 2: 173-177, 2012.
33. Zhang X, Yamamoto N, Soramoto $\mathrm{S}$ and Takenaka I cisplatin-induced germ cell apoptosis in mouse testes. Arch Androl 46: 43-49, 2001

34. Aitken RJ: The amoroso lecture. The human spermatozoon-a cell in crisis? J Reprod Fertil 115: 1-7, 1999.

35. Aitken RJ: Founders' lecture. Human spermatozoa: Fruits of creation, seeds of doubt. Reprod Fertil Dev 16: 655-664, 2004.

36. Peltola V, Huhtaniemi I and Ahotupa M: Antioxidant enzyme activity in the maturing rat testis. J Androl 13: 450-455, 1992

37. Zini A and Schlegel PN: Catalase mRNA Expression in the male rat reproductive tract. J Androl 17: 473-480, 1996.

38. Al-Bader M and Kilarkaje N: Effects of bleomycin, etoposide and cisplatin treatment on Leydig cell structure and transcription of steroidogenic enzymes in rat testis. Eur J Pharmacol 747: $150-159,2015$.

39. Berger CC, Bokemeyer C, Schuppert F and Schmoll HJ: Endocrinological late effects after chemotherapy for testicular cancer. Br J Cancer 73: 1108-1114, 1996.

40. Bieber AM, Marcon L, Hales BF and Robaire B: Effects of chemotherapeutic agents for testicular cancer on the male rat reproductive system, spermatozoa, and fertility. J Androl 27: 189-200, 2006

41. Delbès $G$, Chan D, Pakarinen $P$, Trasler JM, Hales BF and Robaire B: Impact of the chemotherapy cocktail used to treat testicular cancer on the gene expression profile of germ cells from male Brown-Norway rats. Biol Reprod 80: 320-327, 2009.

42. Howell SJ and Shalet SM: Spermatogenesis after cancer treatment: Damage and recovery. J Natl Cancer Inst Monogr 12-17, 2005.

43. Zirak MR, Rahimian R, Ghazi-Khansari M, Abbasi A, Razmi A, Mehr SE, Mousavizadeh K and Dehpour AR: Tropisetron attenuates cisplatin-induced nephrotoxicity in mice. Eur J Pharmacol 738: 222-229, 2014

44. Pavkovic M, Riefke B and Ellinger-Ziegelbauer $\mathrm{H}$ : Urinary microRNA profiling for identification of biomarkers after cisplatin-induced kidney injury. Toxicology 324: 147-157, 2014

45. Yang Y, Liu H, Liu F and Dong Z: Mitochondrial dysregulation and protection in cisplatin nephrotoxicity. Arch Toxicol 88 $1249-1256,2014$

46. Nudell DM, Monoski MM and Lipshultz LI: Common medications and drugs: How they affect male fertility. Urol Clin North Am 29: 965-973, 2002.

47. Ilbey YO, Ozbek E, Cekmen M, Simsek A, Otunctemur A and Somay A: Protective effect of curcumin in cisplatin-induced oxidative injury in rat testis: Mitogen-activated protein kinase and nuclear factor-kappa B signaling pathways. Hum Reprod 24: 1717-1725, 2009.

48. Nalesnik JG, Sabanegh ES Jr, Eng TY and Buchholz TA: Fertility in men after treatment for stage 1 and 2A seminoma. Am J Clin Oncol 27: 584-588, 2004

49. Ozyurt B, Parlaktas BS, Ozyurt H, Aslan H, Ekici F and Atis O: A preliminary study of the levels of testis oxidative stress parameters after MK-801-induced experimental psychosis model: Protective effects of CAPE. Toxicology 230: 83-89, 2007.

50. Calaf GM, Echiburú-Chau C, Roy D, Chai Y, Wen G and Balajee AS: Protective role of curcumin in oxidative stress of breast cells. Oncol Rep 26: 1029-1035, 2011.

51. Zhou M, Fan C and Tian N: Effects of curcumin on the gene expression profile of L-02 cells. Biomed Rep 3: 519-526, 2015.

52. He B, Wei W, Liu J, Xu Y and Zhao G: Synergistic anticancer effect of curcumin and chemotherapy regimen FP in human gastric cancer MGC-803 cells. Oncol Lett 14: 3387-3394, 2017.

53. Jiang S, Yan H, Fan D, Song J and Fan C: Multi-layer electrospun membrane mimicking tendon sheath for prevention of tendon adhesions. Int J Mol Sci 16: 6932-6944, 2015.

54. Wu S, Tao L, Wang JN, Xu ZQ, Wang J, Xue YJ, Huang KY, Lin JF, Li L and Ji KT: Amifostine pretreatment attenuates myocardial ischemia/reperfusion injury by inhibiting apoptosis and oxidative stress. Oxid Med Cell Longev 2017: 4130824, 2017.

55. Chok MK, Conti M, Almolki A, Ferlicot S, Loric S, Dürrbach A, Benoît $G$, Droupy $S$ and Eschwège $P$ : Renoprotective potency of amifostine in rat renal ischaemiareperfusion. Nephrol Dial Transplant 25: 3845-3851, 2010.

56. İkinci A, Mercantepe T, Unal D, Erol HS, Şahin A, Aslan A, Baş O, Erdem H, Sönmez OF, Kaya H and Odacı E: Morphological and antioxidant impairments in the spinal cord of male offspring rats following exposure to a continuous $900 \mathrm{MHz}$ electromagnetic field during early and mid-adolescence. J Chem Neuroanat 75: 99-104, 2016 
57. Du Q, Hao C, Gou J, Li X, Zou K, He X and Li Z: Protective effects of p-nitro caffeic acid phenethyl ester on acute myocardial ischemia-reperfusion injury in rats. Exp Ther Med 11: 1433-1440, 2016.

58. Severi-Aguiar GD, Pinto SJ, Capucho C, Oliveira CA, Diamante MA, Barbieri R, Predes FS and Dolder H: Chronic intake of green propolis negatively affecting the rat testis. Pharmacogn Res 9: 27-33, 2017.

59. Chan D, Delbès G, Landry M, Robaire B and Trasler JM: Epigenetic alterations in sperm DNA associated with testicular cancer treatment. Toxicol Sci 125: 532-543, 2012.

60. Bhimani RS, Troll W, Grunberger D and Frenkel K: Inhibition of oxidative stress in HeLa cells by chemopreventive agents. Cancer Res 53: 4528-4533, 1993

61. Ho C, Hsu YC, Lei CC, Mau SC, Shih YH and Lin CL: Curcumin Rescues Diabetic Renal Fibrosis by Targeting Superoxide-Mediated Wnt Signaling Pathways. Am J Med Sci 351: 286-295, 2016.
62. Jia J, Zhang L, Shi X, Wu M, Zhou X, Liu X and Huo T: SOD2 mediates amifostine-induced protection against glutamate in PC12 cells. Oxid Med Cell Longev 2016: 4202437 , 2016.

63. Schwertheim S, Wein F, Lennartz K, Worm K, Schmid KW and Sheu-Grabellus SY: Curcumin induces G2/M arrest, apoptosis, $\mathrm{NF}-\kappa \mathrm{B}$ inhibition and expression of differentiation genes in thyroid carcinoma cells. J Cancer Res Clin Oncol 143: 1143-1154, 2017.

This work is licensed under a Creative Commons Attribution-NonCommercial-NoDerivatives 4.0 International (CC BY-NC-ND 4.0) License. 